\title{
Fabrication of Nanoparticles of Barium Carbonate/Oxalate Using Reverse Micelle Technique
}

\author{
Poonam Sharma and H.S. Virk ${ }^{*}$ \\ Nanotechnology Laboratory, DAV Institute of Engineering \& Technology, Kabir Nagar, Jalandhar-144008, India
}

\begin{abstract}
Nanoparticles of barium carbonate/oxalate have been synthesized in situ from barium nitrate and ammonium carbonate/oxalate by reverse micelle method. These particles were characterized using transmission electron microscope (TEM), fourier transform infrared (FTIR) and x-ray diffraction (XRD). The results indicate that rod-like barium carbonate $\left(\mathrm{BaCO}_{3}\right)$ and spherical barium oxalate $\left(\mathrm{BaC}_{2} \mathrm{O}_{4}\right)$ nanoparticles can be fabricated with high crystallinity.
\end{abstract}

\section{INTRODUCTION}

Nanostructural materials have become attractive because of their unique characteristics that can hardly be obtained from conventional bulk materials owing to their quantum size and surface effects. So, there has been considerable interest in fabrication of low-dimensional nanosized materials such as nanowires, nanorods and nanotubes because they possess distinctive geometries, novel physical and chemical properties, and have potential applications in nanodevices [1-4] and find diverse applications in nanotechnology $[5,6]$.

Several processes have been explored in the literature for the synthesis of nanomaterials. These processes involve both physical and chemical methods [7-10]. Among all chemical processes shape and size controlled growth of inorganic materials using reverse micelles or micro emulsions has received considerable attention during the recent past and demonstrated as a versatile method to produce a variety of nanoparticles owing to its diverse application potential in areas such as catalysis, medicine, pigments, cosmetics and separation technology $[11,12]$. Here the precipitation is carried out in aqueous cores (nanoreactor) or reverse micelles that have the typical diameter of the order of 5-6 $\mathrm{nm}$. The reverse micelle route of synthesis yields monodisperse nanoparticles with a very high degree of homogeneity as compared with other low temperature route of synthesis. The mechanism for the formation of nanocrystalline materials using reverse micelles has been explained in literature [13-17] by considering the synthesis of a simple compound like metal oxalate and carbonate. Colloidal synthesis is by far the cheapest and has the advantage of being able to occur at benchtop conditions.

A microemulsion system consists of an oil phase, a surfactant and an aqueous phase. It is a thermodynamically stable isotropic dispersion of the aqueous phase in the continuous oil phase. Microemulsion A should be metal ion and $B$ should be oxalate in case of metal oxalate and in case

*Address correspondence to this author at the Nanotechnology Laboratory, DAV Institute of Engineering and Technology, Kabir Nagar, Jalandhar, Punjab - 144008, India; Tel: +91-181-2200126/2200232; Fax: +91-1812207650; E-mail: hardevsingh.virk@gmail.com of metal carbonate, $\mathrm{B}$ should be carbonate. These two microemulsions are mixed by constant stirring and the droplets continuously collide, which results in the interchange of reactants. During this process, the reaction takes place inside the nanoreactor. In microemulsion system, the reverse micelles of metal oxalate/ carbonate forms the fused dimer which finally breaks down into two stable smaller droplets because surface tension becomes high due to large surface area and dimer is unable to sustain its geometry [18].

Most rare earth oxalates and carbonates have wide applications in electro-optical devices and some applications in industry for producing barium salts, pigments and barium ferrite [18]. Barium carbonate $\left(\mathrm{BaCO}_{3}\right)$ is also used as a precursor for producing superconductor and ceramic materials and other important applications in optical glass and electric condensers. Very few efforts have been made in literature for the fabrication of Barium oxalate. Therefore, in the present study, we report the synthesis and characterization of $\mathrm{BaCO}_{3}$ and $\mathrm{BaC}_{2} \mathrm{O}_{4}$ nanoparticles using reverse micelles technique.

\section{MATERIALS AND METHODOLOGY}

\section{(a) Chemicals and Instruments}

Barium nitrate, ammonium oxalate, ammonium carbonate, iso-octane, cetyl trimethyl ammonium bromide (CTAB), methanol and chloroform were purchased from $\mathrm{CDH}$; n-butanol from Loba Chemie, and were of 99\% purity. They were used without further purification. Double distilled water was used in all experiments.

The samples were characterized by using Transmission Electron Microscope (TEM) of FEI 200kV (Netherlands), Fourier Transform Infra-red (FT-IR) of Thermo Nicolet 6700 (USA) using $\mathrm{KBr}$ pellets over the wave number range $400-3500 \mathrm{~cm}^{-1}$ with resolution of $4 \mathrm{~cm}^{-1}$ and X-ray Diffraction (XRD) $\mathrm{X}^{\prime}$ Pert PRO (PANanalytical, Netherlands) using $\mathrm{Cu} \mathrm{K} \alpha$ radiation. TEM and XRD investigations were carried out in Sophisticated Analytical Instrumentation Facility (SAIF), Punjab University, Chandigarh and FTIR studies made in DAV College, Jalandhar. 


\section{(b) Synthesis of Barium Carbonate and Oxalate Nanoparticles}

In a typical experiment, at room temperature, the barium carbonate and oxalate were synthesized by using the reverse micelar route with $\mathrm{CTAB}$ as a surfactant, n-butanol as the co-surfactant and iso-octane as the non-polar solvent. For the synthesis of barium carbonate two different microemulsions, $\mathrm{A}$ and B were used. Microemulsion A $(25 \mathrm{ml})$ is prepared by adding $2.5 \mathrm{ml}$ of $0.1 \mathrm{M}$ aqueous solution of barium nitrate, $3.5 \mathrm{ml}$ of n-butanol as co-surfactant, $15 \mathrm{ml}$ of iso-octane as the non-polar solvent and $4.20 \mathrm{~g}$ of cetyl trimethylammonium bromide (CTAB) as surfactant. Microemulsion B $(25 \mathrm{ml})$ is prepared by adding $2.5 \mathrm{ml}$ of $0.1 \mathrm{M}$ aqueous solution of ammonium carbonate, $3.5 \mathrm{ml}$ of n-butanol as co-surfactant, $15 \mathrm{ml}$ of iso-octane as the non-polar solvent and $4.20 \mathrm{~g}$ of cetyl trimethylammonium bromide (CTAB) as surfactant. Both the microemulsions (A and B) were stirred separately, then mixed slowly and then kept for stirring overnight using a magnetic stirrer. The product was separated from microemulsions by centrifugation and washed with $1: 1$ mixture of chloroform and methanol and dried at room temperature. The flow chart for the synthesis of nanocrystalline barium carbonate is shown in Fig. (1).

The synthesis of barium oxalate was achieved in a similar manner as discussed above for barium carbonate except that the microemulsion $\mathrm{B}$ contains $0.1 \mathrm{M}$ aqueous solution of ammonium oxalate instead of ammonium carbonate. The weight fractions of various constituents in these microemulsions are as follows [14]: $16.76 \%$ of $\mathrm{CTAB}$, $13.90 \%$ of n-butanol, $59.29 \%$ of isooctane and $10.05 \%$ of the aqueous phase. The composition, chemical formulae and purity of components used in microemulsions are given below in Table 1.

The sizes and morphologies of the products were examined by transmission electron microscopy (TEM), while their components and crystal types were determined by Fourier transform infrared spectroscopy (FTIR) and X-ray powder diffractometer (XRD).

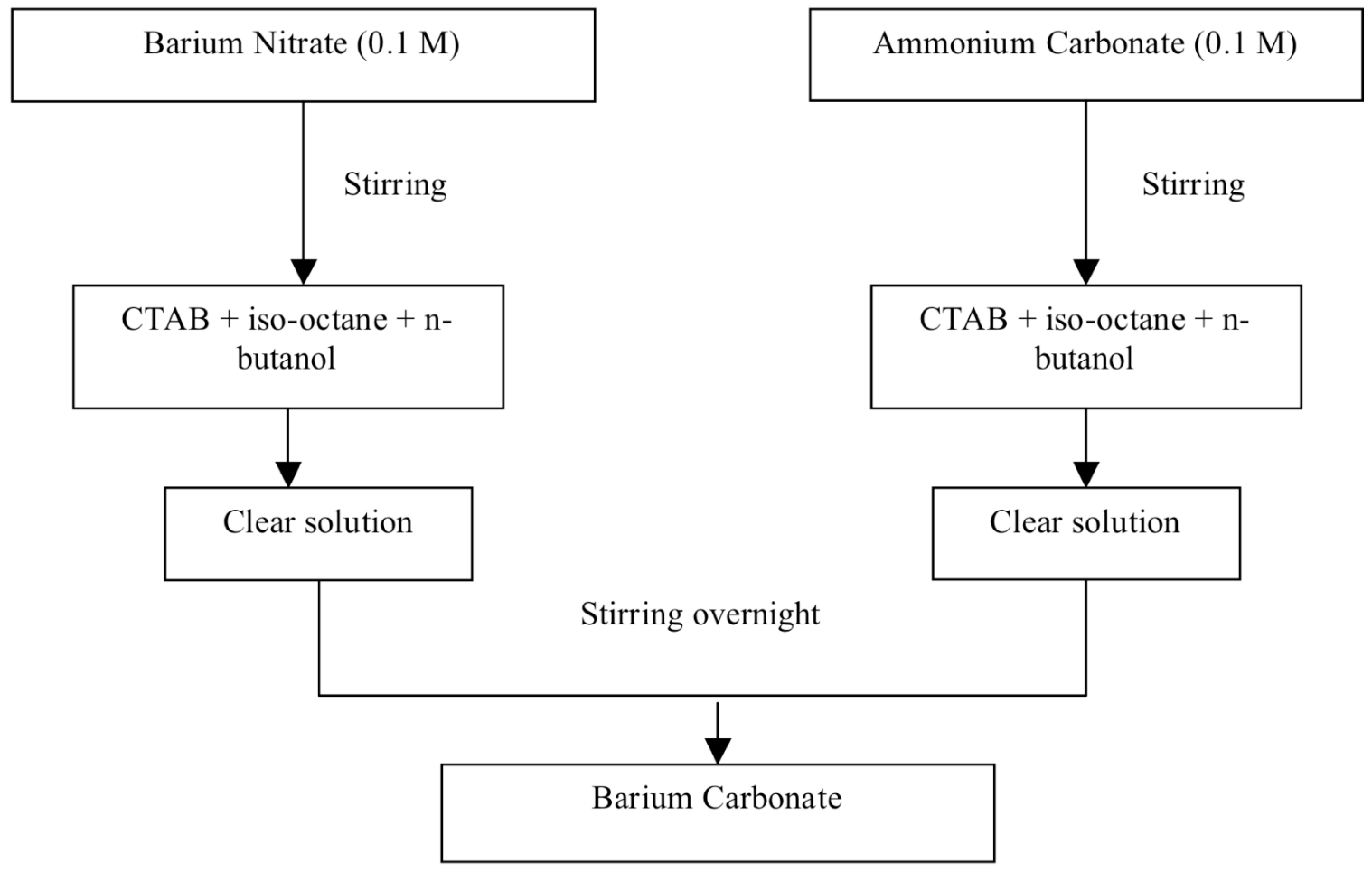

Fig. (1). Flow chart for synthesis of nanocrystalline barium carbonate.

Table 1. Composition, Chemical Formula and Purity of the Components of the Microemulsion

\begin{tabular}{|c|c|c|c|}
\hline S. No. & Chemical Name & Chemical Formula & Purity \\
\hline \hline 1 & Iso-Octane & $\mathrm{C}_{8} \mathrm{H}_{18}$ & $99.00 \%$ \\
\hline 2 & n-butanol & $\mathrm{C}_{4} \mathrm{H}_{10} \mathrm{O}$ & $99.00 \%$ \\
\hline 3 & Ammonium Carbonate & $\mathrm{NH}_{4} \mathrm{HCO}_{3}+\mathrm{NH}_{2} \mathrm{CO}_{2} \mathrm{NH}_{4}$ & $31 \%$ of $\mathrm{NH}_{3}$ equivalent to $95.3 \%$ of $\mathrm{NH}_{4} \mathrm{HCO}_{3}+\mathrm{NH}_{2} \mathrm{CO}_{2} \mathrm{NH}_{4}$ \\
\hline 4 & Ammonium Oxalate & $\left(\mathrm{COONH}_{4}\right)_{2} \mathrm{H}_{2} \mathrm{O}$ & $99.00 \%$ \\
\hline 5 & Barium Nitrate & $\mathrm{Ba}\left(\mathrm{NO}_{3}\right)_{2}$ & $99.00 \%$ \\
\hline 6 & CTAB (Cetytrimethylammoniumbromide $)$ & $\mathrm{C}_{19} \mathrm{H}_{42} \mathrm{BrN}$ & $99.00 \%$ \\
\hline
\end{tabular}




\section{RESULTS AND DISCUSSION}

\section{(a) TEM Micrographs}

Fig. (2a) shows that TEM images of $\mathrm{BaCO}_{3}$ obtained in aqueous solution are rod-like with an average length of $3 \mu \mathrm{m}$ and diameter in the range of $100 \mathrm{~nm}$. The aspect ratio that is the ratio of length to diameter is on the order of 30 . It has been reported [18] that aspect ratio of $\mathrm{BaCO}_{3}$ is 15 and diameter in the range of $100-150 \mathrm{~nm}$. TEM images (Fig. 3a) of $\mathrm{BaC}_{2} \mathrm{O}_{4}$ nanoparticles grown in reverse micelles (with $\mathrm{CTAB}$ ) differ markedly from those of $\mathrm{BaCO}_{3}$. It may be seen that $\mathrm{BaC}_{2} \mathrm{O}_{4}$ particles obtained are spherical in shape with diameter in the range of $20-50 \mathrm{~nm}$. Selected area electron diffraction (SAED) pattern (Figs. 2b, 3b) obtained for $\mathrm{BaCO}_{3}$ and $\mathrm{BaC}_{2} \mathrm{O}_{4}$ show a number of spots arranged in circular manner which confirms the nanocrystalline nature of grown nanoparticles.

(a)

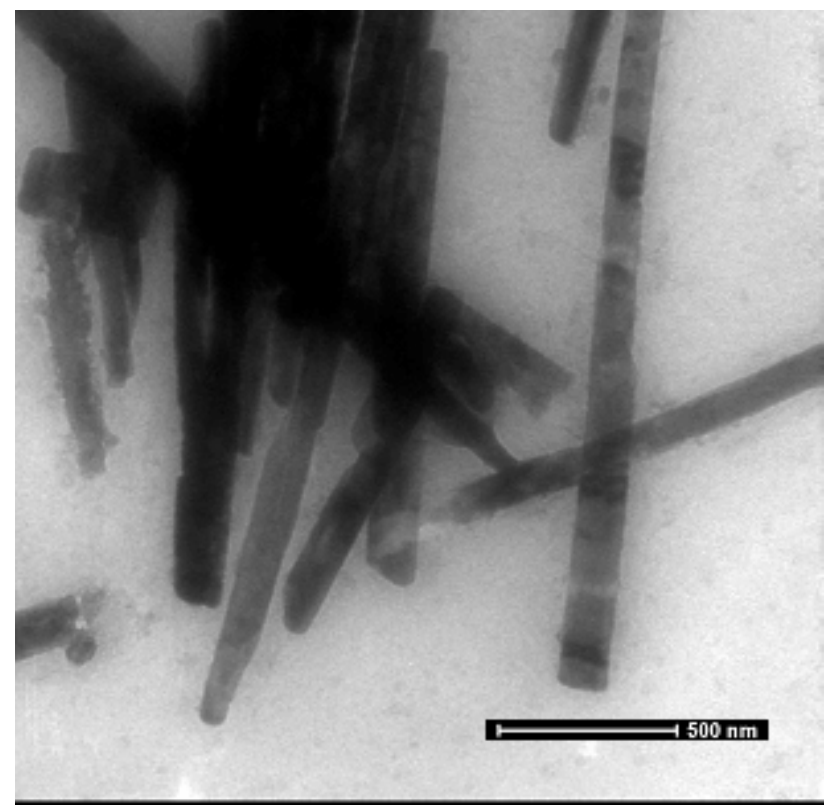

(b)

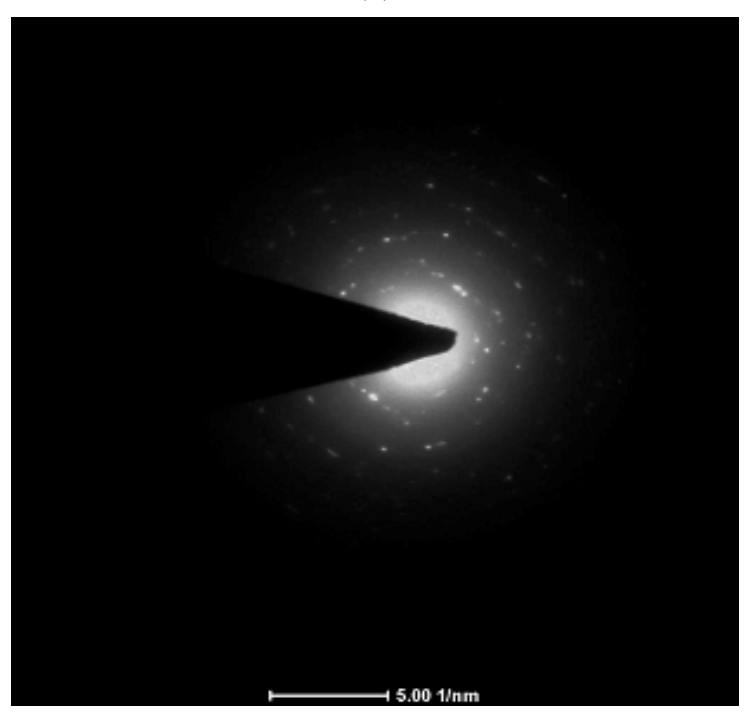

Fig. (2). (a) TEM image of barium carbonate $\left(\mathrm{BaCO}_{3}\right)$ (b) Selected area electron diffraction micrographs of barium carbonate $\left(\mathrm{BaCO}_{3}\right)$. (a)

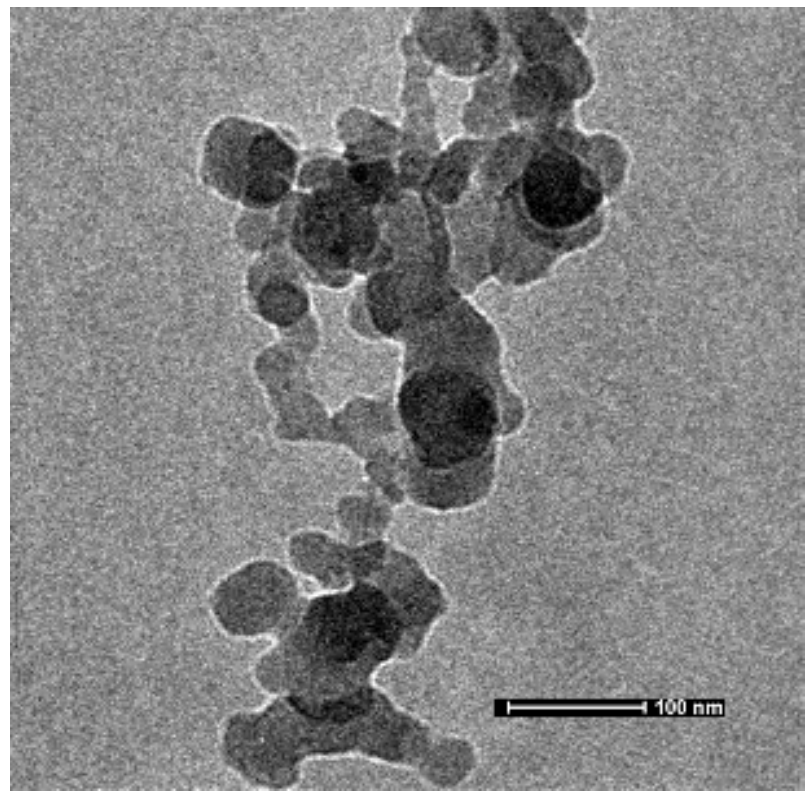

(b)

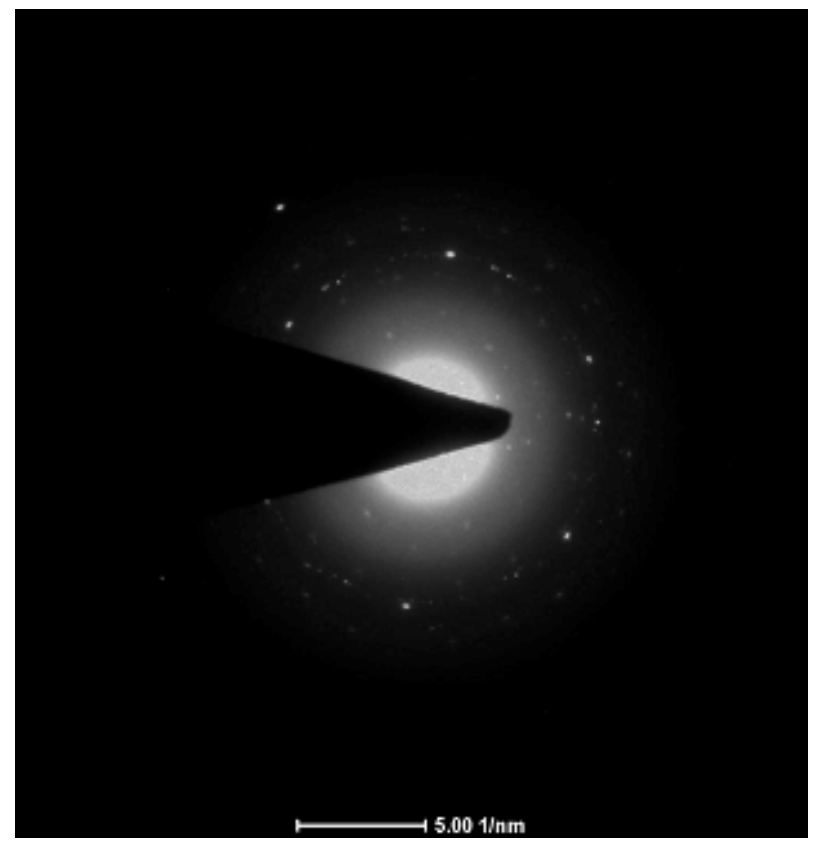

Fig. (3). (a) TEM image of barium oxalate $\left(\mathrm{BaC}_{2} \mathrm{O}_{4}\right)$ (b) Selected area electron diffraction micrographs of barium oxalate $\left(\mathrm{BaC}_{2} \mathrm{O}_{4}\right)$.

\section{(b) XRD Spectra}

The x-ray diffraction patterns of $\mathrm{BaCO}_{3}$ and $\mathrm{BaC}_{2} \mathrm{O}_{4}$ are shown in Fig. $(\mathbf{4 a}, \mathbf{b})$. XRD pattern of $\mathrm{BaCO}_{3}$ displays some diffraction peaks corresponding to $2 \theta: 6.79^{\circ}, 17.06^{\circ}, 19.48^{\circ}$, $20.53^{\circ}, 23.96^{\circ}, 27.54^{\circ} 34.47^{\circ}, 38.13^{\circ}, 42.05^{\circ}$, with most prominent peak at $23.96^{\circ}$. This peak can be correlated to (111) hkl indices of pure orthorhombic witherite structure of $\mathrm{BaCO}_{3}$, suggesting that $\mathrm{BaCO}_{3}$ crystals mainly grow along the (111) face [18]. The XRD pattern of $\mathrm{BaC}_{2} \mathrm{O}_{4}$ (Fig. $4 \mathbf{b}$ ) displays a number of diffraction peaks corresponding to $2 \theta$ : $18.36^{\circ}, 23.75^{\circ}, 26.17^{\circ}, 28.18^{\circ}, 29.01^{\circ}, 35.53^{\circ}, 39.68^{\circ}, 41.16^{\circ}$, $43.28^{\circ}$, with most prominent peak at $28.18^{\circ}$. This peak can be correlated to (200) hkl indices, predicting a monoclinic 


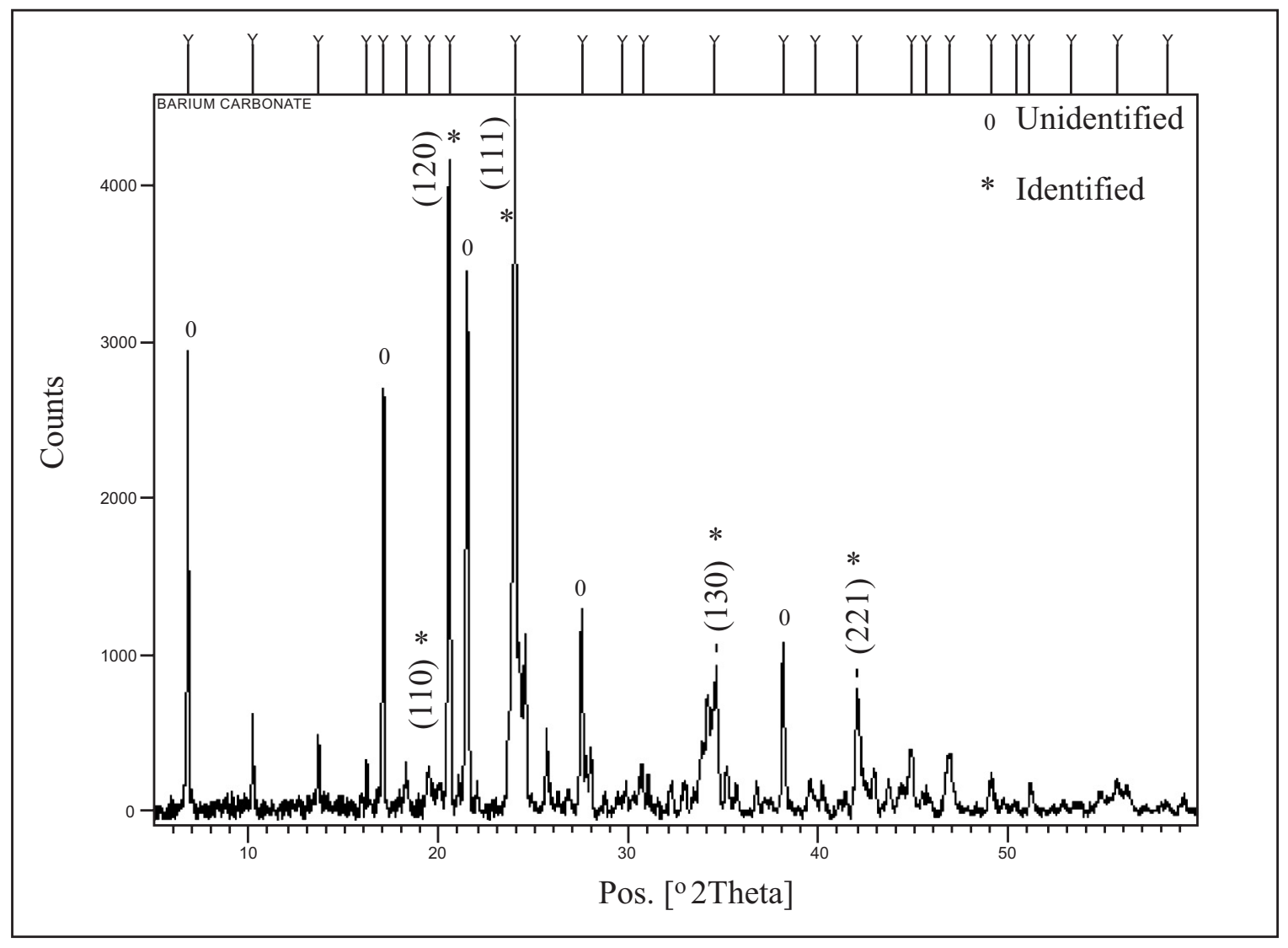

Fig. (4a). X-ray diffraction pattern of barium carbonate $\left(\mathrm{BaCO}_{3}\right)$.

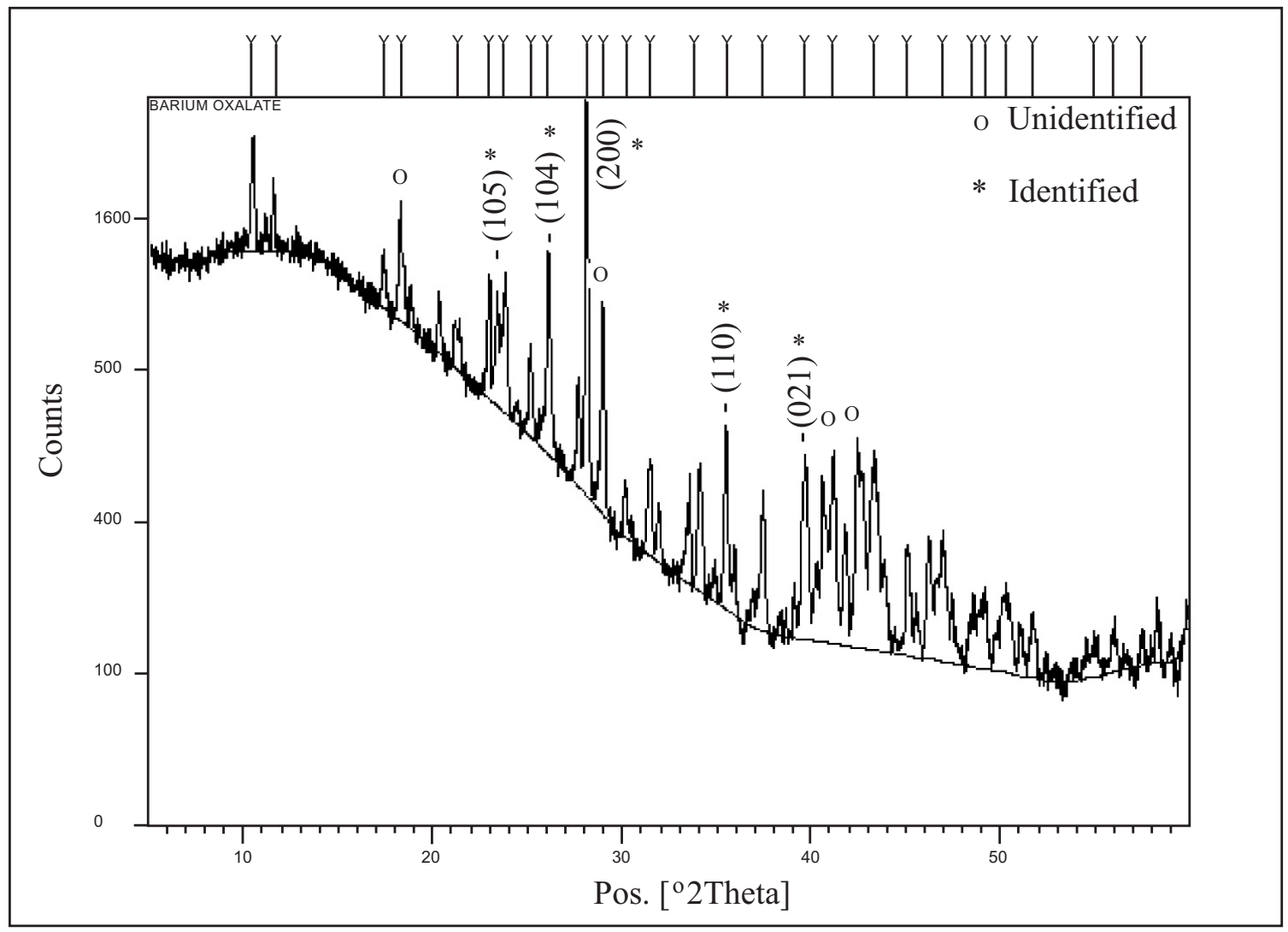

Fig. (4b). X-ray diffraction pattern of barium oxalate $\left(\mathrm{BaC}_{2} \mathrm{O}_{4}\right)$. 
structure of $\mathrm{BaC}_{2} \mathrm{O}_{4}$ [19] and growth of nanoparticles along the face (200). Along with other several strong diffraction peaks, XRD pattern suggest that the crystallinity of $\mathrm{BaCO}_{3}$ and $\mathrm{BaC}_{2} \mathrm{O}_{4}$ nanoparticles obtained is excellent, as already established by the TEM (SAED) micrographs. This crystallinity may be attributed to interfacial homogeneity nucleation in reverse micelles. The size of the nanoparticles was also calculated by the width of highest peak (FWHM) using Debye-Scherrer's formula [20] and was found to be in fair agreement with size calculated using TEM measurements.

\section{(c) FTIR Spectra}

Fig. $(\mathbf{5 a}, \mathbf{b})$ shows FTIR spectra of $\mathrm{BaCO}_{3}$ and $\mathrm{BaC}_{2} \mathrm{O}_{4}$ in reverse micelles. The IR spectrum in the range $400-3500 \mathrm{~cm}^{-1}$ show well pronounced broad intense peaks in case of $\mathrm{BaCO}_{3}$

(a)

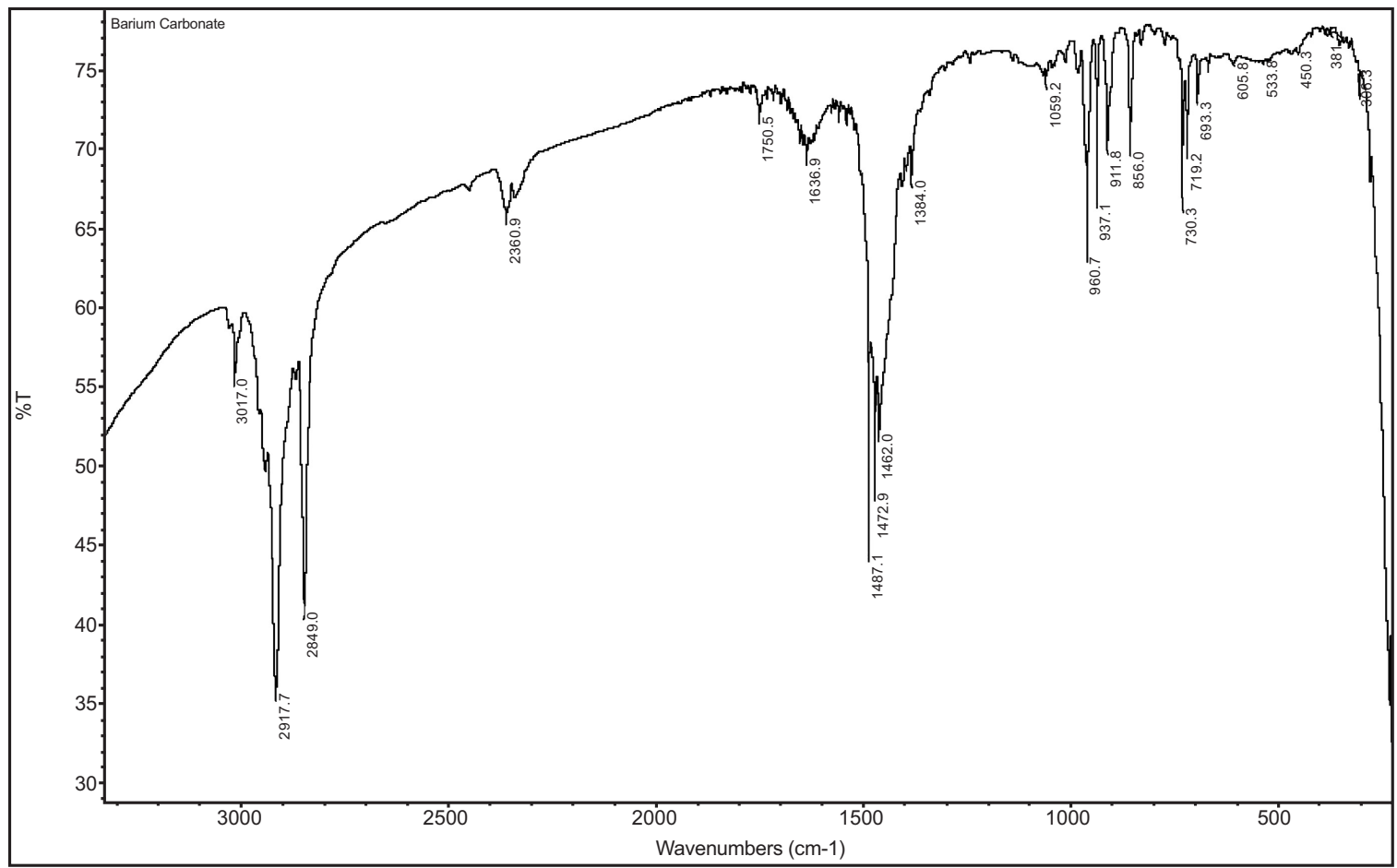

(b)

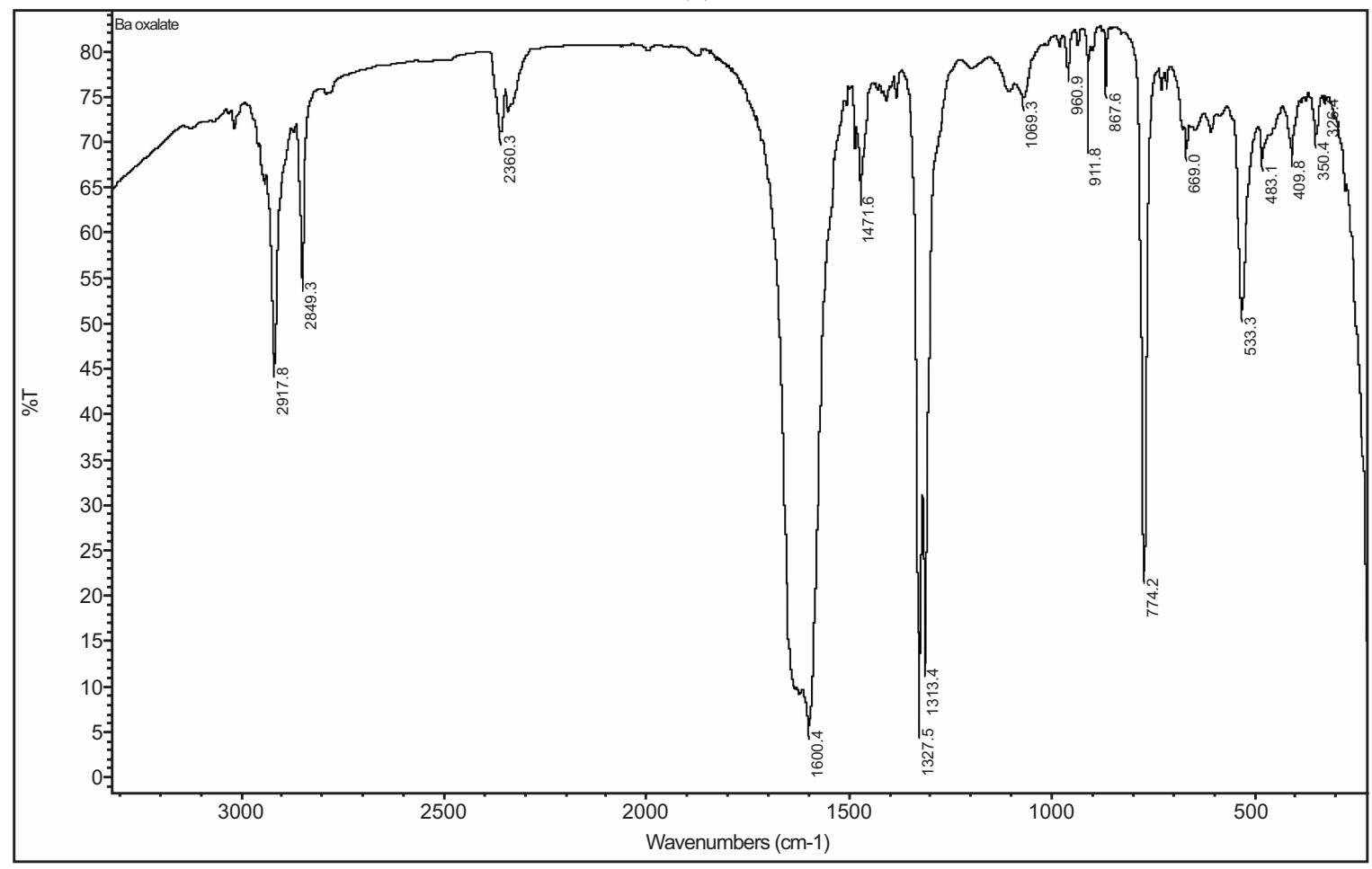

Fig. (5). Fourier transform infra-red spectra of (a) Barium carbonate $\left(\mathrm{BaCO}_{3}\right)$ and (b) Barium oxalate $\left(\mathrm{BaC}_{2} \mathrm{O}_{4}\right)$. 
and $\mathrm{BaC}_{2} \mathrm{O}_{4}$. The observed IR bands and their assignments are shown in Table 2.

FTIR spectra of $\mathrm{BaCO}_{3}$ have been studied [18] to determine the effect of surfactant on the microstructure of nanocrystals. It was found that $\mathrm{CTAB}$ and water/oil interface have no influence on the microstructure of $\mathrm{BaCO}_{3}$. FTIR spectrum of $\mathrm{BaC}_{2} \mathrm{O}_{4}$ shows a well pronounced peak at 1600.4 $\mathrm{cm}^{-1}$ due to $\mathrm{O}-\mathrm{H}$ bending vibration, which established the presence of water molecule associated with nanocrystals. The IR band at $1313.4 \mathrm{~cm}^{-1}$ corresponds to the asymmetric stretching mode of C-O bond. The sharp peak at $867.6 \mathrm{~cm}^{-1}$ confirmed the bonding of metal-oxygen (M-O bond) [21].

Table 2. Assignment of IR Band Frequencies $\left(\mathrm{cm}^{-1}\right)$

\begin{tabular}{|c|c|c|}
\hline S. No. & Barium Carbonate & Assignments \\
\hline \hline 1. & 693.3 and 856 & $\begin{array}{c}\text { In plane and out plane } \\
\text { Bending } \mathrm{CO}_{3}^{-2}\end{array}$ \\
\hline 2. & 1462 & Asymmetric C-O stretching vibration \\
\hline S. No. & Barium Oxalate & Assignments \\
\hline 1. & 1600.4 & O-H bending \\
\hline 2. & 1313.4 & C-O bond \\
\hline 3. & 867.6 & M-O bond \\
\hline
\end{tabular}

\section{CONCLUSION}

We have demonstrated the formation of nanoparticles of Barium carbonate/oxalate through the microemulsion method. Nanoparticles of Barium carbonate are rod-like whereas those of Barium oxalate are spherical in shape which is confirmed by TEM micrographs. The crystalline nature of Barium carbonate/oxalate is confirmed by XRD spectra whereas FTIR spectra confirm the structural features of Barium carbonate/oxalate nanoparticles.

\section{ACKNOWLEDGEMENTS}

The authors wish to acknowledge the financial support provided by the Principal, DAV Institute of Engineering \& Technology, Jalandhar and DAV College Managing Committee, New Delhi to set up Research Centre and Nanotechnology Laboratory in DAVIET, Jalandhar. They thankfully acknowledge the technical help rendered by Mr. Vishal Baloria and Mr. Sanjeev Mahajan during this experiment.

\section{REFERENCES}

[1] Park JN, Koo B, Yoon KY, et al. Generalized synthesis of metal phosphide nanorods via thermal decomposition of continuously delivered metal-phosphine complexes using a syringe pump. J Am Chem Soc 2005; 127: 8433

[2] Zhang DE, Zhang XJ, Ni XM, Zheng HG, Yang DD. Synthesis and characterization of $\mathrm{NiFe}_{2} \mathrm{O}_{4}$ magnetic nanorods via a PEG-assisted route. J Magn Mater 2005; 292: 79.

[3] Xia BY, Yang PD, Sun YG, et al. One-dimensional nanostructures: Synthesis, characterization, and applications. Adv Mater 2003; 15: 353.

[4] Duan X, Huang Y, Cui Y, Wang J, Lieber CM. Indium phosphide nanowires as building blocks for nanoscale electronic and optoelectronic devices. Nature 2001; 409: 66.

[5] Li YH, Kotzeva VP, Fray DJ. Electrochemical performance of CdS nanomaterials synthesized by microemulsion techniques. Mater Lett 2006; 60: 2743.

[6] Liu WJ, He WD, Zhang ZC, et al. Fabrication of CdS nanorods in inverse microemulsion using HEC as a template by a convenient $\gamma$ irradiation technique. J Cryst Growth 2006; 290: 592.

[7] Schaefar JE, Kisker H, Kronmuller H, Wurschum R. Magnetic properties of nanocrystalline nickel. Nanostruct Mater 1992; 1: 523.

[8] Komarneni S, D’Arrigo MC, Leionelli C, Pellacani GC, Katsuki H. Microwave hydrothermal synthesis of nanophase ferrites. J Am Ceram Soc 1998; 81: 3041.

[9] Phule PP, Grundy DC. Pathways for the low temperature synthesis of nano-sized crystalline barium zirconate. Mater Sci Eng B 1994; 23: 29 .

[10] ChatterjeeA, Das D, Pradhan SK, Chakravorty D. Synthesis of nanocrystalline nickel-zinc ferrite by the sol-gel method. J Magn Magn Mater 1993; 127: 214.

[11] Pileni MP, Gulik-Krzywicki T, Tanori J, Filankembo A, Dedieu JC. Template design of microreactors with colloidal assemblies: Control the growth of copper metal rods. Langmuir 1998; 14:7359.

[12] Rees GD, Evans-Gowing R, Mammond SJ, Robinson BH. Formation and morphology of calcium sulfate nanoparticles and nanowires in water-in-oil microemulsions. Langmuir 1999; 15: 1993

[13] Ahmad T, Chopra R, Ramanujachary KV, Lofland SE, Ganguly AK. Nanorods of copper and nickel oxalates synthesized by the reverse micellar route. Nanosci Nanotechnol 2005; 5: 1840.

[14] Ahmad T, Ramanujachary KV, Lofland SE, Ganguly AK Nanorods of manganese oxalate: a single source precursor to different manganese oxide nanoparticles $\left(\mathrm{MnO}, \mathrm{Mn}_{2} \mathrm{O}_{3}, \mathrm{Mn}_{3} \mathrm{O}_{4}\right)$. J Mater Chem 2004; 14: 3406

[15] Ahmad T, Vaidya S, Sarkar N, Ghosh S, Ganguly AK. Zinc oxalate nanorods: A convenient precursor to uniform nanoparticles of $\mathrm{ZnO}$. Nanotechnology 2006; 17: 1236.

[16] Ganguly AK, Ahmad T. Nanorods of iron oxalate synthesized using reverse micelles: facile route for $\mathrm{Fe} 2 \mathrm{O} 3$ and $\mathrm{Fe} 3 \mathrm{O} 4$ nanoparticles. J Nanosci Nanotechnol 2007; 7: 2029.

[17] Macketta JJ. Encycyclopedia of chemical processing and design. Marcel Dekker: New York 1997; pp. 51

[18] Chen L, Shen Y, Xie A, Zhu J, Wu Z, Yang L. Nanosized barium carbonate particles stabilized by cetyltrimethylammonium bromide at the water/hexamethylene interface. Cryst Res Technol 2007; 42: 886.

[19] Dalal PV, Saraf KB, Shah S. Growth of barium oxalate crystals in agar-agar gel and their characterization. Cryst Res Technol 2009; 44: 36 .

[20] Guinier A. X- ray Diffraction. Freeman: San Francisco 1963.

[21] Packter A, Omon A. The co-precipitation of Magnesium Nickel Oxalate Dihydrate powders (solid solutions) from aqueous solution: Precipitate compositions and co-precipitate mechanisms. Cryst ResTechnol 1984; 19: 467. 